\title{
Diet, obesity, and metabolic control in girls with insulin dependent diabetes mellitus
}

\author{
K H Pietiläinen, S M Virtanen, A Rissanen, H Rita, J Mäenpää
}

\begin{abstract}
Objective-To investigate whether girls with insulin dependent diabetes mellitus (IDDM) were more overweight than nondiabetic girls, and how diet, insulin treatment, metabolic control, age, and pubertal status were related to body weight and fat content.

Design-Case-control study.

Subjects and methods-48 IDDM girls aged 10-19 years and controls matched for age and social class participated in the study. Overweight was assessed by body mass index (BMI), relative weight, and body fat from skinfold thicknesses. Food consumption data were collected by a 48 hour recall method.

Results-The girls with IDDM were more overweight than control girls according to all measures of obesity (for example, mean BMI $20.3 v 18.9 \mathrm{~kg} / \mathrm{m}^{2}$ ). The daily insulin dose/body weight correlated positively with BMI and per cent body fat. Conclusions-Girls with IDDM are more overweight than their peers, which indicates that a more effective prevention of obesity is needed in the treatment of diabetes.

(Arch Dis Child 1995; 73: 398-402)
\end{abstract}

Keywords: insulin dependent diabetes mellitus, diet, obesity, metabolic control.

Department of Applied Chemistry and Microbiology, Division of Nutrition, University of Helsinki, Finland

K H Pietiläinen

$S M$ Virtanen

Helsinki University Central Hospital

A Rissanen

Department of Forest

Resource

Management/Statistics, University of Helsinki H Rita

Department of Paediatrics and Adolescent Clinic, Aurora Hospital, Helsinki

J Mäenpäă

Correspondence and reprint requests to: Kirsi H Pietiläinen, c/o Suvi M Virtanen, Department of Applied Chemistry and Microbiology, Division of Nutrition, Division of Nutrition,

FIN-00014, University of Helsinki, Helsinki, Finland.

Accepted 12 July 1995
Children and adolescents with insulin dependent diabetes mellitus (IDDM) have been found to be more prone to a high body mass index (BMI) than their non-diabetic counterparts and unaffected siblings, ${ }^{1-4}$ although some studies do not confirm this finding. ${ }^{56}$ Although it is a readily available and therefore widely used index, BMI is not a good measure of relative fatness. ${ }^{7}$ Nevertheless, body composition has seldom been assessed in diabetic children and adolescents. Gregory et al studied the body composition of young diabetic subjects by skinfold thickness and bioelectrical impedance measurements and found a high mean body fat among diabetic girls during and after puberty, ${ }^{8}$ but since there were no control subjects in their study, the normal increase in body fatness during puberty could not be estimated accurately.

In some series, multiple insulin injection treatment has been associated with a high BMI, ${ }^{910}$ and overweight has been accompanied both by frequent hypoglycaemic episodes and by poor metabolic control, that is, high glycated haemoglobin $\mathrm{A}_{1 \mathrm{c}}\left(\mathrm{HbA}_{1 \mathrm{c}}\right)$ values. ${ }^{9-11} \mathrm{~A}$ high $\mathrm{BMI}$ has not always indicated poor metabolic control, however. ${ }^{6}$
This study was designed to examine whether adolescent diabetic girls were more overweight than non-diabetic girls when BMI, relative weight (a percentage of the median for height and sex), and per cent body fat were used as indicators of adiposity. We also analysed how diet, insulin treatment, metabolic control, age, and pubertal status were related to body weight and fat content.

\section{Methods}

SUBJECTS

All of the 10-19 year old diabetic girls attending the diabetes clinic and the adolescent clinic of Aurora Hospital in Helsinki were invited to participate in this study, which was carried out from March to June 1993. Of the 74 diabetic girls invited, $48(65 \%)$ complied. The participants were younger than the non-participants, at $13.7(\mathrm{SD} 2.9) v 15.6(2.5)$ years, $\mathrm{p}<0.01$, respectively. The age adjusted BMI of the participants was lower than that of the nonparticipants, at $20.3(3.0) v 21.9(2.9) \mathrm{kg} / \mathrm{m}^{2}$, $\mathrm{p}<0.001$. The participants also had lower mean $\mathrm{HbA}_{1 \mathrm{c}}$ during the preceeding year than the non-participants, at $9.3(1.7) \% \quad v \quad 10.3$ $(1.8) \%, p<0.05$. The mean duration of diabetes among the participating girls was 5.0 $(4 \cdot 3)$ years. More than half $(58 \%)$ of these girls followed a multiple insulin injection regimen (four or more injections per day), 38\% took insulin three times, and $4 \%$ twice daily. The mean daily insulin dose was $0.90(0.2) \mathrm{IU} / \mathrm{kg}$ body weight.

One non-diabetic control girl was selected for each diabetic girl invited. Of the 74 control girls invited, $58(79 \%)$ participated, but only those 48 whose diabetic pair also participated were included in the present analyses. Control girls were recruited from five local schools and matched for age (to the nearest 0.5 year) and social class with the diabetic girls. The subjects' socioeconomic status was classified into three categories according to the better placed parent ${ }^{12}$ as follows: (1) employers, self employed, and upper level employees (classes I-III, $\mathrm{n}=21$ ), (2) lower level employees (class $\mathrm{IV}, \mathrm{n}=20$ ), (3) manual workers (class $\mathrm{V}, \mathrm{n}=7$ ).

Both diabetic and control girls were on average 13.7 years old (range $10 \cdot 1-19.5$ years). To study the effect of age on energy intake and obesity, the subjects were subdivided into two groups: 10-13 year olds $(n=23)$ and 14-19 year olds $(n=25)$. The assessment of pubertal status, based on pubic hair and breast development and the method of Marshall and Tanner, ${ }^{13}$ was made by their treating physicians in the IDDM girls and by one of the authors (SMV, MD) in the control girls. Of 
the diabetic girls, 12 were prepubertal (Tanner stage 1), 17 pubertal (Tanner stages 2-4), and 19 postpubertal (Tanner stage 5). Of the control girls, 10 were prepubertal, 27 pubertal, and 11 postpubertal. Twenty five of the diabetic girls and 23 of the control girls were postmenarcheal. No statistical differences were found between diabetic and control girls in these variables.

\section{ANTHROPOMETRIC MEASUREMENTS}

Body height and weight were measured with the subjects wearing light underwear and no shoes. Height was measured to the next succeeding $0.5 \mathrm{~cm}$ and weight to the nearest $0.1 \mathrm{~kg}$. BMI $\left(\mathrm{kg} / \mathrm{m}^{2}\right)$ was calculated, and relative weight, expressed as a percentage of the median for age and sex, was assessed from the national growth charts. ${ }^{14}$ Skinfold thicknesses (triceps, biceps, and subscapular) were measured according to Tanner and Whitehouse ${ }^{15}$ using a Harpenden skinfold caliper (John Bull, British Indicators), and the body fat percentage was estimated from the skinfold thicknesses using the regression equations of Slaughter et al. ${ }^{16}$ The anthropometric measurements were made by a nutritionist (KHP) who also interviewed the subjects.

\section{DIETARY ASSESSMENT}

A 48 hour recall interview was used to obtain detailed data on the kind and amount of food consumed by the subjects during the two days preceeding the interview. A separate room was reserved for the interviews. The subjects did not know the interviewer or the nature of the interview beforehand. The confidentiality of the study was emphasised in order to minimise any tendency towards selective reporting. The subject estimated the size of the portion of food with the aid of dishes, a portion size booklet, ${ }^{17}$ or samples of local foods. Data on food eaten at school lunches were checked using the menus and other information obtained from the schools. Data on home food, for example the quality of fat used in food preparation, were collected from the parents. The food consumption data were processed using specific library programs ${ }^{18}$ developed for dietary studies. The food composition files were based mainly on Finnish food composition tables and analytical data obtained from the local industry, and were supplemented by data from foreign food composition tables when no other data were available. The data on the dietary fibre composition of foods were from the Finnish dietary fibre study, 1920 in which the fibre was analysed by the method of Englyst. ${ }^{21}$ The consumption of foods and nutrients was calculated separately for the two days studied. The mean daily consumption of foods and intakes of energy and 30 nutrients were computed.

\section{LABORATORY MEASUREMENTS}

The mean $\mathrm{HbA}_{1 \mathrm{c}}$ values of the preceeding year (on average 4.2 measurements per person) were used as an indicator of metabolic control. $\mathrm{HbA}_{1 \mathrm{c}}$ was measured by high performance liquid chromatography (HPLC) using Biorad equipment (Japan) (non-diabetic range of $\mathrm{HbA}_{1 \mathrm{c}}$ 4-6\%). To exclude diabetic girls with a substantial amount of endogenous insulin excretion, that is, those in partial remission, the associations between metabolic control, diet, and obesity were further analysed only among the 30 girls who had a daily insulin dose of greater than $0.50 \mathrm{IU} / \mathrm{kg}$ body weight and the duration of diabetes longer than two years. ${ }^{22}$

\section{STATISTICAL ANALYSES}

Statistical analyses were performed by the SAS statistical package. Student's $t$ test for related samples was used to compare the differences between diabetic and control girls and elsewhere the $t$ test for unrelated samples was applied. Analysis of variance was used to estimate the associations between the three pubertal status groups and overweight. Normality of distribution was assessed by the Wilk-Shapiro test, and for skewed distributions a logarithmical transformation of the variable was used in further analyses. Pearson and Spearman correlations were used, when appropriate, to evaluate the linear associations between variables characterising age, diet, overweight, metabolic control, and glucose home monitoring. Analysis of covariance (age as a covariate) was used when analysing whether the $\mathrm{BMI}$ and $\mathrm{HbA}_{1 \mathrm{c}}$ values were different between the participants and the nonparticipants. Multiple linear regression analysis was used for studying the combined effects of diet and obesity on metabolic control. Values are given as mean (SD).

\section{Results}

ANTHROPOMETRIC AND CLINICAL CHARACTERISTICS

The mean height of diabetic and control girls was similar, but the groups differed in mean weight, BMI, relative weight, and per cent of body fat (table 1). All these variables showed

Table 1 Anthropometric characteristics of the subjects studied; values are mean (SD) and range. Difference values are mean (SEM)

\begin{tabular}{lccl}
\hline & $\begin{array}{l}\text { Diabetic girls } \\
(n=48)\end{array}$ & $\begin{array}{l}\text { Control girls } \\
(n=48)\end{array}$ & Difference \\
\hline Height (m) & $156 \cdot 6(13 \cdot 6)$ & $156 \cdot 4(11 \cdot 7)$ & $0 \cdot 002(0 \cdot 03)$ \\
& $131 \cdot 2-179 \cdot 0$ & $132 \cdot 5-177 \cdot 0$ & \\
Weight (kg) & $50 \cdot 9(13 \cdot 6)$ & $47 \cdot 2(12 \cdot 4)$ & $3 \cdot 7(1 \cdot 5)^{\star}$ \\
& $24 \cdot 5-81 \cdot 6$ & $27 \cdot 6-81 \cdot 6$ & \\
BMI (kg/m $\left.{ }^{2}\right)$ & $20 \cdot 3(3 \cdot 0)$ & $18 \cdot 9(2 \cdot 7)$ & $1 \cdot 4(0 \cdot 5) \dagger$ \\
& $13 \cdot 6-26 \cdot 8$ & $13 \cdot 4-26 \cdot 0$ & \\
Relative weight (\%) & $111(13)$ & $103(12)$ & $8 \cdot 0(2 \cdot 4) \dagger$ \\
& $88-142$ & $76-133$ & \\
Skinfolds (mm) & & & \\
Biceps & $11 \cdot 8(6 \cdot 0)$ & $9 \cdot 2(4 \cdot 5)$ & $2 \cdot 6(1 \cdot 1)^{\star}$ \\
Triceps & $3 \cdot 2-35 \cdot 0$ & $3 \cdot 8-24 \cdot 4$ & \\
& $18 \cdot 0(7 \cdot 2)$ & $14 \cdot 7(4 \cdot 3)$ & $3 \cdot 4(1 \cdot 2) \dagger$ \\
Subscapular & $7 \cdot 8-34 \cdot 5$ & $7 \cdot 1-24 \cdot 4$ & \\
& $12 \cdot 2(5 \cdot 6)$ & $9 \cdot 5(3 \cdot 6)$ & $2 \cdot 7(0 \cdot 9) \dagger$ \\
Body fat (\%) & $5 \cdot 2-38 \cdot 2$ & $4 \cdot 4-23 \cdot 8$ & \\
& $25 \cdot 2(7 \cdot 5)$ & $21 \cdot 5(4 \cdot 9)$ & $3 \cdot 7(1 \cdot 18) \dagger$ \\
& $13 \cdot 2-48 \cdot 7$ & $11 \cdot 1-31 \cdot 0$ & \\
\hline
\end{tabular}

$\mathrm{BMI}=$ body mass index

${ }^{\star} \mathrm{p}<0.05, \mathrm{tp}<0.01$ (diabetic $v$ control). 
Table 2 Anthropometric characteristics of the subjects in two age groups; values are mean (SD). Difference values are mean (SEM)

\begin{tabular}{|c|c|c|c|c|c|c|}
\hline & \multicolumn{3}{|c|}{ Age 10-13 years } & \multicolumn{3}{|c|}{ Age $14-19$ years } \\
\hline & $\begin{array}{l}\text { Diabetic } \\
(n=23)\end{array}$ & $\begin{array}{l}\text { Control } \\
(n=23)\end{array}$ & Difference & $\begin{array}{l}\text { Diabetic } \\
(n=25)\end{array}$ & $\begin{array}{l}\text { Control } \\
(n=25)\end{array}$ & Difference \\
\hline $\begin{array}{l}\text { Relative weight } \\
\text { BMI }\left(\mathrm{kg} / \mathrm{m}^{2}\right) \\
\text { Body fat }(\%)\end{array}$ & $\begin{array}{l}105(10) \\
18 \cdot 3(2 \cdot 3) \\
21 \cdot 3(6 \cdot 4)\end{array}$ & $\begin{array}{l}98(11) \\
17 \cdot 2(2 \cdot 1) \\
19 \cdot 0(4 \cdot 5)\end{array}$ & $\begin{array}{l}6.9(3.3)^{\star} \\
1 \cdot 1(0.6) \\
2 \cdot 3(1.7)\end{array}$ & $\begin{array}{l}116(13) \\
22 \cdot 2(2 \cdot 4) \\
28 \cdot 7(6 \cdot 7)\end{array}$ & $\begin{array}{c}107(10) \\
20 \cdot 5(2 \cdot 1) \\
23 \cdot 8(4 \cdot 2)\end{array}$ & $\begin{array}{l}9.0(3 \cdot 6)^{\star} \\
1.7(0.7)^{\star} \\
5.0(1 \cdot 7) \dagger\end{array}$ \\
\hline
\end{tabular}

${ }^{\star} \mathrm{p}<0.05, \mathrm{tp}<0.01$ (diabetic $v$ control). In both diabetic and control girls, the difference

between younger and older age group was significant $(p<0.001)$ for all the variables.

that diabetic girls were on average more overweight than control girls. Among the 14-19 year olds, the differences between diabetic and control girls were marked, but among the 10-13 year olds, only the relative weight was slightly higher in diabetic girls (table 2). Postpubertal girls with IDDM had more body fat than non-diabetic girls past puberty (28.9 $v 22.6 \%$, respectively, $\mathrm{p}<0.05)$. Body weight and composition measurements did not differ between diabetic and control girls in prepubertal and pubertal subgroups.

In both diabetic and control girls, all the body weight and composition measurements correlated with age $(r=0.41-0.69, \mathrm{p}<0.005)$. The age adjusted insulin dose/body weight correlated positively with BMI $(r=0.31$, $\mathrm{p}=0.03)$ and per cent body fat $(r=0.34$, $\mathrm{p}=0.02$ ), but not significantly with relative weight $(r=0.23, \mathrm{p}=0.12, \mathrm{NS})$. Those following multiple insulin injection regimens (four or more daily injections) had a higher BMI and percentage of body fat than those on conventional treatment (two to three injections daily), but when age was taken into account, the differences became non-significant.

The metabolic control of diabetic girls was generally poor. The mean $\mathrm{HbA}_{1 \mathrm{c}}$ of the preceeding year was $9 \cdot 3(1 \cdot 7) \%$. In the 30 diabetic girls who were considered not to have a substantial amount of their own insulin excretion, the mean $\mathrm{HbA}_{1 \mathrm{c}}$ was $9.9(1 \cdot 7) \%$. In a linear regression model for the 30 girls past partial remission, the per cent of body fat and the energy adjusted intake of saturated fat were positively related to $\mathrm{HbA}_{1 \mathrm{c}}$ (table 3 ), whereas no significant relationship could be found between $\mathrm{HbA}_{1 \mathrm{c}}$ and $\mathrm{BMI}$ or between $\mathrm{HbA}_{1 \mathrm{c}}$ and relative weight.

Forty per cent of the diabetic girls reported adjusting their insulin doses 'every or every second day' to compensate for variations in the diet and activity, 38\% did the adjustment 'two to three times a week', and $23 \%$ less or not at

Table 3 Variables explaining $(p<0.05)$ poor metabolic control (high $\mathrm{Hb} \mathrm{A}_{1 \mathrm{c}}$ ) in regression models among diabetic girls past partial remission $(n=30)$. The equation in the $j^{\text {th }}$ case is: $y_{\mathrm{j}}=a+\sum b_{\mathrm{i}} x_{\mathrm{ij}}$, where $a$ is the intercept, $b$ the parameter estimate, $x_{\mathrm{ij}}$ the value of the determinant

\begin{tabular}{|c|c|c|c|}
\hline & $b$ & $S E$ & $p$ \\
\hline Intercept (a) & $58 \cdot 8$ & & \\
\hline Body fat $(\%)^{\star}$ & 0.82 & 0.35 & 0.03 \\
\hline $\begin{array}{l}\text { Energy adjusted intake of } \\
\text { saturated fatty acids }\end{array}$ & $1 \cdot 20$ & 0.59 & 0.05 \\
\hline $\begin{array}{l}\text { Fit of the model } \\
r^{2}=0.25 \quad F \text { value }=4.4\end{array}$ & degree & reedom $=1$ & $p=0$ \\
\hline
\end{tabular}

^From skinfold thickness measurements.
Table 4 Daily intake of foods in grammes per $1000 \mathrm{kcal}$ in diabetic and control girls. Values are mean (SD)

\begin{tabular}{lcc}
\hline & $\begin{array}{c}\text { Diabetic } \\
(n=48)\end{array}$ & $\begin{array}{c}\text { Control } \\
(n=48)\end{array}$ \\
\hline Cereal products & $91(29)$ & $87(34)$ \\
Potato & $52(43)$ & $56(46)$ \\
Vegetables & $93(98)$ & $67(56)$ \\
Fruit and berries & $199(144)$ & $146(144)$ \\
Butter, margarine and oils & $17(8)$ & $18(7)$ \\
Milk and milk products & $317(159)$ & $302(151)$ \\
Meat and meat products & $59(36)$ & $52(35)$ \\
Fish, fish products, and eggs & $18(22)$ & $23(25)$ \\
Beverages, sugar, and other foods & $319(226)$ & $411(301)$
\end{tabular}

${ }^{\star}$ Logarithmically transformed for the $t$ test.

all. Metabolic control was not related to the degree of adjustment in these small subgroups. Of diabetic girls, $96 \%$ had monitored blood glucose (median for all the girls with IDDM $=20$, range $0-40$ ) and $48 \%$ urinary glucose (median for all the girls with $\mathrm{IDDM}=0$, range 0-20) during the previous month. The monitoring of both blood and urinary glucose correlated negatively to age $(r=-0.4, \mathrm{p}<0.01$, for both), but the frequency of monitoring was not related to metabolic control.

INTAKE OF FOODS, ENERGY, AND NUTRIENTS

The mean daily consumption of foods in relation to energy content of the diet did not differ between diabetic and control girls (table 4). The diet of diabetic girls contained slightly more energy $(1912 \mathrm{kcal})$ than that of control girls (1719 kcal, $\mathrm{p}=0.04)$ (table 5). In the two age groups, $10-13 v 14-19$ years of age, the mean daily energy content of the diet was similar in diabetic girls (1973v $1856 \mathrm{kcal}, \mathrm{NS})$, but differed in control girls (1590 $v 1839 \mathrm{kcal}, \mathrm{p}=0.03$ ). Thus in the younger age group diabetic girls received

Table 5 Daily intake of energy, and nutrient intake per 1000 kcal in diabetic and control girls. Values are mean (SD)

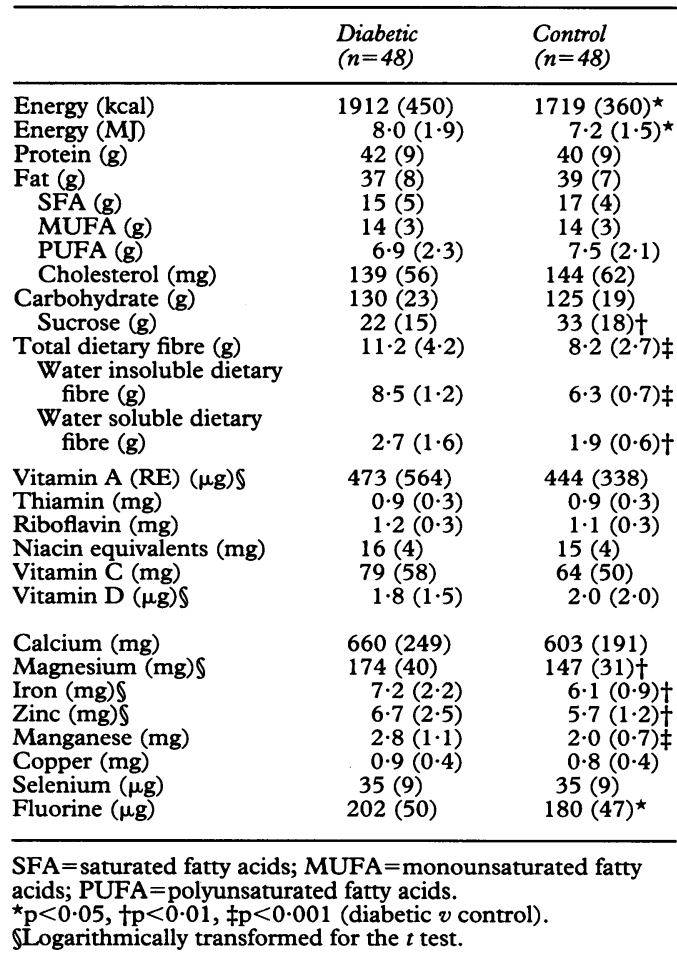


more energy than control girls of the same age $(p<0.001)$, whereas there were no differences in the older age group. The age adjusted correlation between energy (or fat) intake and the variables characterising adiposity showed no significance either in diabetic or in control girls.

The proportions of energy derived from protein $(17 \% v 16 \%)$, fat $(34 \% v 35 \%)$, and carbohydrate $(50 \% v 49 \%)$ were similar in the diets of diabetic and control girls. There were no differences between the groups in the proportions of energy derived from saturated fatty acids ( $14 \% v 15 \%)$, monounsaturated fatty acids $(12 \% v 13 \%)$, or polyunsaturated fatty acids $(6 \% v 7 \%)$, but the proportion of sucrose was lower in the diet of diabetic than in that of control girls ( $9 \%$ v 13\%, $\mathrm{p}=0.002)$.

Diabetic girls obtained more dietary fibre than control girls (table 5). The vitamin density of the diet did not differ between diabetic and control girls. Of the minerals, diabetic girls received relatively more potassium, magnesium, iron, zinc, manganese, and fluorine than control girls.

\section{Discussion}

Increasing overweight, assessed by $\mathrm{BMI}$, has recently been reported as a problem in IDDM subjects during and after puberty, ${ }^{1-4}$ although this has been disputed. ${ }^{5} 6$ There are few published data on body composition in IDDM subjects, although this is a more accurate way of defining obesity. In a British study, ${ }^{8}$ fat accumulation was found to be a problem of pubertal girls with IDDM, but the lack of a control group hampered the conclusions. In our study, diabetic girls were noticeably more overweight than control girls according to BMI, relative weight, and anthropometric assessments. The differences between diabetic and control girls were more distinct in the older age group (14-19 years) and in the postpubertal group.

The prevalence rates for obesity are dependent on the reference values chosen. Using the national growth charts, ${ }^{14}$ and the criterion for obesity of $>120 \%$ of the median for age and sex, as many as $25 \%$ of diabetic girls $(n=12)$ were considered to be obese, but there was a normal prevalence in control girls $(6 \%, n=3)$. The prevalence of obesity was $13 \%$ in diabetic girls and $4 \%$ in control girls when the 90th centile of BMI from a Finnish nationwide study ${ }^{23}$ was used as the criterion for obesity. When the 90th centiles of triceps skinfold of the Finnish ${ }^{23}$ and British ${ }^{15}$ reference values were used, the corresponding prevalence for obesity was $25 \%$ in diabetic girls and $13 \%$ in control girls, but according to American reference data, ${ }^{24} 15 \%$ of diabetic and $2 \%$ of control girls were obese. Compared with the results from the study of Dahlström et $a l^{23}$ control girls of the present study were representative of average. Finnish adolescents, but diabetic girls were noticeably more obese.

The higher prevalence of obesity among diabetic girls may explain why they were less willing to participate in this study than control girls (participation rates being 65\% v 79\%, respectively). The non-participating diabetic girls were found to have a higher mean BMI than the girls who did take part. Because of this participation bias, the real difference in adiposity between diabetic and control girls could have been even greater than the observed difference.

The seemingly large weight gain of diabetic girls during puberty could be explained by the fact that they had a higher energy intake than control girls, especially those in the younger age group. However, the energy intake did not correlate with the variables measuring body weight and composition and thus could not account for the differences in adiposity between the groups. Multiple insulin injection regimens, a possible factor associated with weight gain in the treatment of diabetes, ${ }^{910}$ have become a common treatment method in Finland in recent years. Between 1985 and 1993, the number of diabetic subjects having four or more daily injections increased from $0 \%$ to $58 \%$, and at the same time the mean insulin dose/unit body weight increased from 0.79 to $0.90 \mathrm{IU} / \mathrm{kg}$, as suggested by Virtanen's data ${ }^{22}$ and by this study. In the present study, multiple insulin injection regimens could not be shown to be related to adiposity, but the daily insulin dose/unit body weight correlated positively with BMI and with the percentage of body fat. An unnecessarily high insulin dose after the growth spurt leads to increased energy intake and increased storage of extra energy, which, according to this study, seems to be the natural cause of obesity in girls with IDDM.

Poor metabolic control is common in adolescent patients with IDDM. ${ }^{1011} \mathrm{~A}$ high BMI was related to poor metabolic control in the study of Virtanen, ${ }^{11}$ which is in agreement with the association between high body fat and high $\mathrm{HbA}_{1 \mathrm{c}}$ values found in this study. On the other hand, overweight diabetic adolescents did not have worse metabolic control than those in the study by Abusrewil and Savage. ${ }^{6}$

A high intake of saturated fat was associated with poor metabolic control in this study. A diet high in saturated fat could thus be thought to be an indicator of dietary negligence in both the treatment of diabetes and the prevention of obesity. In the light of this study, we believe that a low intake of saturated fat could help in achieving better metabolic control, in addition to the known beneficial effects of such a diet in the prevention of cardiovascular diseases.

The recommended proportions of energy from total fat $(<30 \%)$, saturated fatty acids $(<10 \%)$, carbohydrates $(50-55 \%)$, and protein $(15 \%)^{25} 26$ were not achieved by either the diabetic or the control girls. Because of the allowance of sucrose in the present recommendations, ${ }^{25}$ the sucrose intake has markedly increased in IDDM subjects, from $4 \%$ of energy in $1985^{5}$ to $9 \%$ in this study. However, the daily sucrose intake was still lower in diabetic girls than in control girls, and was within the recommended range $(<10 \%$ of total energy intake) in the diabetic girls. The nutrient densities of several vitamins and 
minerals and of dietary fibre in the diabetic girls' diet had decreased from our earlier study. ${ }^{527}$ Although the fibre intake was still noticeably higher in diabetic than in control girls, it did not reach the recommended level of $15-20 \mathrm{~g} / 1000 \mathrm{kcal}^{26}$ in either of the groups. In both diabetic and control girls, the intake of vitamin $\mathrm{D}$ was low - only about $30 \%$ of the recommended daily allowance. ${ }^{28}$ In diabetic subjects, the average intakes of other vitamins and minerals were in the recommended range, but control subjects had low intakes of iron, zinc, magnesium, and calcium, as has been observed in previous studies. ${ }^{529}$

In summary, diabetic girls were found to be more overweight than their non-diabetic counterparts and also more obese than average Finnish adolescent girls. In diabetic girls, the degree of overweight correlated positively with insulin dose. A high percentage body fat and a high intake of saturated fat were found to be associated with poor metabolic control. Girls with IDDM had slightly higher energy intake than their nondiabetic counterparts, but the energy intake was not associated with adiposity. The diet of the diabetic girls contained less sucrose and more dietary fibre and minerals than that of control girls. In view of the potential hazards of obesity on long term physical and mental health of IDDM patients, more effective prevention and treatment of overweight should be considered as a part of the treatment of diabetes.

1 Steel JM, Young RJ, Lloyd GG, Macintyre CCA. Abnormal eating attitudes in young insulin-dependent diabetics. Br F Psychiatry 1989; 155: 515-21.

2 Peveler RC, Fairburn CG, Boller I, Dunger D. Eating disorders in adolescents with IDDM: a controlled study. Diabetes Care 1992; 15: 1356-60.

3 Thon A, Heinze E, Feilen KD, et al. Development of height and weight in children with diabetes mellitus: report on two prospective multicenter studies, one cross-sectional, one longitudinal. Eur $\mathcal{F}$ Pediatr 1992; 151: 258-62.

4 Holl RW, Heinze E, Seifert M, Grabert M, Teller WM. Longitudinal analysis of somatic development in
paediatric patients with IDDM - genetic influences on height and weight. Diabetologia 1994; 37: 925-9.

5 Virtanen SM, Räsänen L, Mäenpää J, Âkerblom HK. Dietary survey of Finnish adolescent diabetics and nondiabetic controls. Acta Paediatr Scand 1987; 76: 801-8.
Abusrewil SS, Savage DCL. Obesity and diabetic control. Arch Dis Child 1989; 64: 1313-5.

7 Roche AF, Siervogel RM, Chumlea WC, Webb P. Grading body fatness from limited anthropometric data. $A m \mathcal{F}$ Clin Nutr 1981; 34: 2831-8.

8 Gregory JW, Wilson AC, Greene SA. Body fat and overweight among children and adolescents with diabetes mellitus. Diabetic Med 1992; 9: 344-8.

9 DCCT Research Group. Weight gain associated with intensive therapy in the Diabetes Control and Complications Trial. Diabetes Care 1988; 11: 567-73.

10 Mortensen HB, Hartling SG, Petersen KE, and the Danish Study Group of Diabetes in Childhood. A nation-wide cross-sectional study of glycosylated haemoglobin in Danish children with type 1 diabetes. Diabetic Med 1988; 5: 871-6.

11 Virtanen SM. Metabolic control and diet in Finnish diabetic adolescents. Acta Paediatr Scand 1992; 81: 239-43.

12 Central Statistical Office of Finland. Classification of socio-economic status. Classification of occupational status. Helsinki: Valtion painatuskeskus, 1983. Handbook No 17. 13 Marshall WA, Tanner JM. Variations in the pattern of pubertal

14 Sorva R, Perheentupa J, Tolppanen EM. A novel format for a growth chart. Acta Paediatr Scand 1984; 73: 527-9.

15 Tanner JM, Whitehouse RH. Revised standards for triceps and subscapular skinfolds in British children. Arch Dis Child 1975; 50: 142-5.

16 Slaughter MH, Lohman TG, Boileau RA, et al. Skinfold equations for estimation of body fatness in children and youth. Hum Biol 1988; 60: 709-23.

17 Haapa E, Toponen T, Pietinen P, Räsänen L. Annoskuvakirja (Portion Size Booklet, in Finnish). Annoskuvakirja (Portion Size Booklet, in Finnish). of Helsinki, Department of Nutrition, 1985.

18 Ahlström A, Räsänen L, Kuvaja K. A method of data processing for food-consumption surveys. Ann Acad Sci
and processing for food-consumption
Fenn 1972; A IV, 194: 1-8.

19 Varo $P$, Laine R, Veijalainen K, Pero K, Koivistoinen P. Dietary fibre and available carbohydrates in Finnish cereal products. F Agric Sci Finland 1984; 56: 39-48.

20 Varo P, Laine R, Veijalainen K, Espo A, Wetterhoff A, Koivistoinen P. Dietary fibre and available carbohydrates in Finnish vegetables and fruits. $\mathcal{F}$ Agric Sci Finland 1984; 56: 49-59.

21 Englyst H. Determination of carbohydrate and its composition in plant materials. In: James WTP, Theander O, eds. The analysis of dietary fibre in food. New York: Marcel Dekker, 1981: 71-93.

22 Virtanen SM. Diet and metabolic control in Finnish diabetic adolescents and young adults [Dissertation]. Helsinki: Yliopistopaino, 1992.

23 Dahlström S, Viikari J, Åkerblom HK, et al. Atherosclerosis precursors in Finnish children and adolescents. II. precursors in Finnish children and adolescents. II. Height, weight, body mass index, and skinfolds, and their correlation to metabolic

24 Cronk CE, Roche AF. Race and sex-specific reference data for triceps and subscapular skinfolds and weight/stature ${ }^{2}$. Am $\mathcal{F}$ Clin Nutr 1982; 35: 347-54.

25 Finnish Diabetes Association. Dietary recommendations for diabetic subjects 1988 (in Finnish). Diabetes Lääkäriliite 1988: Dec 1-7.

26 State Advisory Board on Nutrition. Dietary guidelines and their scientific principles. Resume of the committee report 1987:3. Helsinki: Valtion painatuskeskus, 1987.

27 Virtanen SM, Varo P. Dietary fibre and fibre fractions in the diet of Finnish diabetic and non-diabetic adolescents. Eur f Clin Nutr 1988; 42: 169-75.

28 Food and Nutrition Board. Recommended dietary allowances. 10th revised edition. Washington DC: National Research 10th revised edition. Washington DC: National

29 Räsänen L, Laitinen S, Stirkkinen R, et al. Composition of the diet of young Finns in 1986. Ann Med 1991; 23: $73-80$. 